\title{
Compreendendo a ação assistencial
}

\author{
José Pedro Simões Neto
}

\section{Resumo}

O artigo "compreendendo a Ação Assistencial" enfoca a assistência social sob o ponto de vista da sociologia e, particularmente, da perspectiva da ação. Assim, recuperando autores clássicos do pensamento sociológico - como Simmel e Jacobson, e Tocqueville -, busca-se matizar quais os elementos que tornam a ação compreensível, a saber: seu contexto, seus agentes e suas formas de ação, além de enfocar o próprio objeto da assistência, o social. Seguindo este fio condutor, o artigo subdivide-se em três partes principais: a abordagem do social como uma nova questão, posta pelo capitalismo; as ações públicas e privadas e a assistência como um campo de relações de poder. Por fim, o texto mostra que a ação assistencial encerra dilemas difíceis de serem superados.

Palauras-chave: Ação Assistencial, Ação Social, Assistência Social, Sociologia.

\section{Introdução}

A assistência social é uma área de intervençáo e de políticas sociais que vem sendo objeto, principalmente, de investigaçóes no campo da ciência política, da economia e das políticas públicas ${ }^{2}$. No entanto, essa área não tem recebido o mesmo tratamento dos pesquisadores da sociologia. Este artigo pretende contribuir para um debate acerca da assistência social a partir do ponto de vista da ação. Nesse sentido, o que está em questão é: sociologicamente, como a ação assistencial é estruturada? De um lado, há componentes políticos e "estruturais” que determinam a ação. Isto significa que, na ação assistencial, há elementos que independem os sujeitos envolvidos. Por outro lado, há elementos que envolvem a capacidade discricionária dos sujeitos. Além de considerar

I Doutor em Sociologia. Professor do Departamento de Sociologia e Ciência Politica da Universidade Federal de Santa Catarina. E-mail: josepeneto@gmail.com

2 Este artigo é parte da pesquisa "Assistência Social e Religião: um estudo do Espiritismo", financiada pelo CNPq (Edital Universal, 2013). 
o contexto ("estrutura"), a capacidade de agência dos indivíduos ("ação"), é preciso considerar, também, o objeto da ação, ou seja, o que é o social da assistência social. Este artigo, portanto, é um ensaio que busca clarificar estes três pontos, recorrendo a autores da sociologia, como Simmel e Jacobson (1965), Tocqueville (2003), Berger e Luckmann (2011), entre outros.

Este artigo está dividido em quatro partes: a primeira parte enfoca o social, como uma nova questão, própria ao capitalismo; a segunda, aborda as relações entre ação pública e privada; a terceira, trata a ação assistencial como uma relação de poder, envolvendo a "sociedade" e os "assistidos". Por fim, são apresentados alguns dilemas da ação assistencial.

\section{Uma nova questão}

O primeiro ponto a ressaltar é que a assistência social não uma prática que ocorreu "desde sempre". O que contemporaneamente se compreende como prática assistencial teve como marco o processo de trabalho decorrente da revolução industrial. É no bojo das transformações do século XIX que surge uma "nova pobreza", denominada à época, como pauperismo (HIMMELFARB, 1991).

Por que as novas relaçóes sociais, derivadas das transaçóes capitalistas, construíram socialmente uma "nova" pobreza e uma "nova" assistência social? Quem analisa este fenômeno é Castel (1998), em Metamorfoses da Questão Social. Em seu estudo, o referido autor demonstra que um conjunto de fatores, como a passagem das formas de vida do mundo rural para o urbano, a quebra das lealdades comunitárias, a instauração das relaçóes individualistas e contratuais e a ausência de uma rede de proteção social estatal, acarreta uma progressiva dissociação das relaçóes sociais.

A discussão das dissociaçóes em Castel (1998) é uma derivação do debate sobre anomia social de Durkheim (1995). Em "Da Divisão do Trabalho Social", o autor afirma que a crescente divisão do trabalho provoca uma perda da moralidade social, ou seja, as pessoas passam a não saber mais como devem se portar em sociedade, perdendo, inclusive o sentido de vida coletiva. Com isso, há um esgarçamento do tecido social. E é este ponto que Castel (1998) se apropria para o seu debate.

A dissociaçáo é uma perda de vínculos sociais. A partir do momento em que as relaçôes em família e de vizinhança se enfraquecem e na medida em 
que as pessoas passam a agir mais para si mesmas, decorrentes do aumento do individualismo, cresce na sociedade a proporção dos indivíduos que se veem cada vez mais sozinhos e desamparados. O que é novo no século XIX é que o "desamparo" dos indivíduos pauperizados, nesta época, não encontrava mais a rede de proteção da vizinhança, da família, ou mesmo nas relações de senhorio (os servos que tinham na aristocracia o instrumento de proteção). É nesse contexto que surgiu, na sociedade, uma pobreza desamparada e que não tem vínculos sociais que a sustentem e a integrem. Antes disso, segundo Castel (1998), a família e a comunidade incorporavam os indivíduos desamparados, de modo que nấo houvesse o risco da desfiliação, integrando-os permanentemente em sua dinâmica.

A assistência social moderna não é tão somente uma forma de ajuda entre aqueles que têm para aqueles que não têm (independentemente do objeto da assistência). Ela envolve uma forma de garantir a integração social evitando a dissociaçáo, ou seja, criando vínculos. Assim, essa discussão retornou ao debate quando a assistência social passou a ser referenciada ao conceito de vulnerabilidade social, como se verá adiante. O que se quer afirmar, neste momento, é que a assistência não está relacionada, exclusivamente, à existência da pobreza enquanto tal - ou seja, de indivíduos com menos recursos do que exigido pelo seu tempo ${ }^{3}$ - mas à necessidade de a sociedade ter de oferecer, pela primeira vez, uma resposta social para o desamparo de uma quantidade cada vez maior de indivíduos. Em um primeiro momento (liberal), a resposta foi oferecida pelos próprios indivíduos; em um segundo, pelo Estado. A diferenciação de respostas será analisada no próximo item.

\section{Público e privado}

O autor que analisa a diferença entre açóes públicas e privadas de assistência social é Tocqueville. Em seu livro "Ensaio sobre a Pobreza" (2003), esse autor inicia sua análise com um paradoxo: as cidades mais ricas por ele observadas (no século XIX) eram, também, as que experimentavam maior número de pobres. Não deveria ser o contrário, ou seja, os pobres estarem concentrados nas cidades (e regiôes) mais pobres?

30 conceito de pobreza é relativo ao tempo e ao contexto social de que se trata. Ver Rocha, 2003. 
A resposta de Tocqueville (2003) é relativamente simples. As cidades que tiveram inicialmente o impulso de industrialização apresentaram níveis de desigualdade social desconhecido nas demais; então, o contraste entre os que possuíam mais e os que possuíam menos tornou-se mais evidente. Além disso, a prosperidade citadina fez com que muitos indivíduos migrassem do campo para a cidade na busca de novos recursos. Neste sentido, as cidades começaram a ficar povoadas, cada vez mais, de pessoas desamparadas e que não tinham qualquer rede de apoio e suporte social. Por outro lado, nas cidades "pobres", havia ainda uma igualdade na pobreza, não sendo a mesma percebida ainda como um problema social.

É neste contexto que Tocqueville (2003) vai tratar da diferenciação entre a "caridade" pública e privada. O autor é um dos formuladores da "Lei dos Pobres" (Poor Law) inglesa (HIMMELFARB, 1991) que tinha como objetivo remediar o crescimento da "nova pobreza". No texto, fica evidente que a existência de indivíduos vivendo à custa do Estado incomodava o autor e sua reflexão vai ao sentido de discutir mecanismos alternativos a essa situação.

Tocqueville observa que a igualdade social só é possível em dois contextos: entre os que nada têm (selvagens) e entre os homens muito civilizados, pois esses dispóem dos meios similares para obterem conforto - na verdade, em um ambiente utópico para o autor. Entre os extremos, há desigualdade, visto que uns têm mais (condições, riquezas e conhecimento) que os outros (pobres e ignorantes).

É no contexto das desigualdades sociais que os indivíduos criam para si um grande contingente de necessidades de "segunda ordem". O autor afirma que fazem parte da primeira ordem as necessidades relativas à constituição física; de segunda ordem são aquelas relativas ao hábito e à educação. Se no primeiro caso, temos a referência à sobrevivência; no segundo, à vida social. Conforme Tocqueville (2003, p. 87), os objetos da "segunda ordem" são aqueles que "[...] não poderiam ser sacrificados em uma vida civilizada"; afinal, é no bojo das "[...] 'novas necessidades' que está a causa da mendicância, desconhecida entre seus ancestrais". 
Para remediar os males sociais ${ }^{4}$, foram estabelecidas formas de caridade (ou beneficência) privada e pública. No primeiro caso, afirma o autor, essa ação consiste em que cada "[...] indivíduo, de acordo com seus meios, amenize os males que vê em torno do si" (TOCQUEVILLE, 2003, p. 91). Este é, para o autor, um ato tão antigo quanto o próprio homem e foi chamado pelo cristianismo de "caridade". No segundo caso, temos um tipo derivado do protestantismo, cuja forma de ação é menos instintiva e mais racional, menos emocional e mais poderosa, fazendo com que a sociedade se mobilize pelas desventuras de seus membros. Já na caridade pública, há uma legitimação da desigualdade: a sociedade permite que o desfrute das riquezas aconteça pari passo com a defesa do pobre contra a miséria excessiva. Nesse modelo, aqueles que têm mais doam (ou pagam impostos) do seu excedente para que outros tenham suas necessidades básicas atendidas (primeira ordem). Portanto, busca-se um equilíbrio na desigualdade: o excesso de uns não pode ser tão grande que contraste com a completa ausência de outros. É essa compensação que a assistência pública busca instituir.

Analisando a experiência inglesa da Poor Law que previa que inspetores locais cobrassem taxas dos habitantes para alimentar os indigentes incapacitados, bem como providenciar trabalho para os outros, Tocqueville (2003) chega às seguintes conclusões: 1 . com estas medidas, a pobreza cresceu mais na Inglaterra do que em qualquer outro país; 2 . uma vez admitido o princípio (direito) à caridade legal, não se pode mais livrar-se dele; 3. do direito à assistência decorre a generalização dos abusos; 4. a caridade retira do homem o desejo de melhorar de vida, uma vez que lhe assegura o necessário para viver, decorrendo em um desestímulo ao trabalho; 5. com isso, a parte ativa da sociedade dedica seus recursos para prover os meios de subsistência àqueles que nada fazem ou que fazem mal uso de seu trabalho; 6. nada é tão difícil de

4 Marx posiciona-se frontalmente contra qualquer tipo de assistência social. Para o autor, tais práticas são ações perpetradas pelos agentes humanitários. O autor assim define esta "escola": "[..] toma a peito o lado mau das relações de produção atuais. Ele procura, para desencargo de consciência, amenizar, ainda que minimamente, os contrastes reais; deplora sinceramente a infelicidade do proletariado, a concorrência desenfreada dos burgueses entre si; aconselha aos operários a sobriedade, o trabalho consciencioso e a limitação dos filhos; recomenda aos burgueses dedicarem-se à produção com entusiasmo refletido. Toda a teoria desta escola assenta sobre as distinções intermináveis entre teoria e prática, os princípios e os resultados, a ideia e a aplicação, o conteúdo e a forma, a essência e a realidade, o direito e o fato, os lados bom e mau" (MARX. 1982, p. I18). 
distinguir quanto as nuances que separam o infortúnio imerecido ${ }^{5}$, ou seja, a adversidade que advenha de hábitos degradantes, de uma situação de necessidade real ${ }^{6}$.

Tocqueville (2003) chama, então, atenção para os paradoxos da assistência: é muito difícil separar aqueles que precisam da assistência daqueles que dela se aproveitam; a verificação da pobreza incorre em um processo de racionalização discutível; ainda que todos devessem trabalhar, como recurso contra a pobreza, o autor reconhece que não há trabalhos para todos; ainda que tivesse trabalho para todos, quem seria o responsável pela imposição do trabalho àqueles que não desejem fazê-lo? Assim pensada, a beneficência pública coloca paradoxos difíceis de serem resolvidos, uma vez que sua aplicação tende a fomentar a dependência e o abuso.

Portanto, o direito à assistência pública, para Tocqueville (2003), não contribui para o equacionamento da questão. Ao contrário, ela coloca problemas que, à sua época, foram vistos como sem solução. A questão principal apontada pelo autor, entretanto, está na ordem do direito. Este último supóe uma igualdade entre as partes (aquele que tem o direito e o que tem o dever). No entanto, essa igualdade não se verifica na assistência.

Nesta perspectiva, há um desnivelamento social entre o assistente e o assistido, pois há uma relação de "inferioridade" entre uns e outros. O direito à assistência é um atestado de incapacidade (inferioridade reconhecida), enquanto os demais direitos são o reconhecimento da contribuição que cada um pode dar para a vida social (base da cidadania).

A partir desses paradoxos, Tocqueville (2003) passa a tratar da beneficência privada. Diferente da pública, a ação direta entre assistente e assistido estabelece ligações (vínculos) entre uns e outros. Enquanto do direito público deriva uma obrigação legal (contrato), sem que exista para isso a constituição de vínculos entre os indivíduos, o mesmo não ocorre com a ação privada: exatamente porque ela não é uma obrigação legal, ela exige algum tipo de envolvimento entre os agentes da ação. Além disso, na ação pública, os recursos

50 autor trabalha com a noção de que o infortúnio merecido é aquele a que o agente não teve agência sobre o mesmo; no infortúnio imerecido, o agente foi o causador pelos seus hábitos degradantes.

6 Afirma o autor: "[...] quem ousaria deixar morrer de fome porque é culpa dele estar morrendo?" (TOCQUEVILLE. 2003, p. 95) 
são derivados de impostos, ou seja, são retirados sem que o agente "doador" deseje fazê-lo. Por outro lado, aquele que recebe o que lhe é de direito não identifica o "doador", não tendo, portanto, gratidão pelo benefício, que de todo modo não o satisfaz.

Logo, o que está em questão é o individualismo moderno ${ }^{7}$. No que tange à "caridade" pública, o individualismo se expressa por meio da profissionalização da prática assistencial. Qual a relação, no entanto, entre caridade pública, individualismo e profissionalização?

A atuação de agentes públicos na administração da assistência social prevê a criação de um sistema de impostos, com sua contrapartida em "benefícios", "programas" ou "políticas sociais". Esse pressuposto já isenta todos aqueles que pagam seus impostos a se interessarem pelos "assistidos", uma vez que já existem servidores públicos para atuarem com esse objetivo. Os pagantes podem voltar-se exclusivamente para seus interesses privados, atribuindo ao governo ou aos agentes da assistência a responsabilidade pelo crescimento da pobreza ou pela sua má gestão da assistência social.

Além disso, o individualismo apresenta-se segundo outra conotação. A profissionalização da assistência social transforma-a em uma ação técnica-instrumental. A tecnificação da ação e sua instrumentalidade retiram qualquer forma de vínculo entre "assistente" e "assistido", conformando-a nos moldes do contrato social. Nesse tipo de relação, o agente público é pago para exercer sua função, aplicando um conjunto de técnicas aprendidas, com uma finalidade estabelecida institucionalmente. Uma vez cumprida sua função profissional, e havendo o pagamento pelo cumprimento de sua tarefa (salário), cessa completamente a relação do agente com a instituição e com aqueles a quem prestou serviço. Desta forma, a ação profissional não é discriminatória, ou seja, ela deve ser exercida independentemente de quem seja o assistido. Portanto, a relação contratual, ao substituir as formas de relação pessoalizadas, é a base para comportamentos individualistas, racionais e instrumentais.

Por outro lado, o estabelecimento do contrato faz com que o assistido se desinteresse pelo agente público, uma vez que seu foco é o objeto do seu direito.

7 O debate sobre individualismo é amplo e não pode ser completamente tratado neste momento. Ver Dumont, 2000. 
Sua ação também não é discriminatória: não importa quem seja o agente, seus direitos são os mesmos e ele tenderá a agir da mesma forma.

Por fim, o estabelecimento do contrato, a partir do direito à assistência, ainda contém uma última conotação: ao desresponsabilizar a sociedade da caridade privada, as ações de assistência se restringem àquelas estabelecidas contratualmente. Como o Estado e as políticas por ele estabelecidas não são onipresentes e não são capazes de avaliar com precisão todos os casos de necessidade, haverá sempre um contingente a descoberto que estará à margem das políticas. Nesse grupo estão também aqueles que, embora precisem, não desejam submeter-se às práticas institucionais de assistência social (questão que será abordada adiante).

Há outro ponto a ser abordado no que concerne aos vínculos estabelecidos pela assistência social; afinal, ao enfatizar a existência de vínculos na caridade privada, Tocqueville (2003) refere-se a um elemento básico de "coesão social”. As pessoas formam uma sociedade não apenas porque vivem conjuntamente mas também por interessarem-se umas pelas outras, estabelecendo vínculos e relações diretas entre si. $\mathrm{O}$ direito à assistência rompe com esse interesse mútuo, por estabelecer relações mediadas pelo contrato institucional. Os agentes da ação, servidores do estado e assistidos, passam a estar vinculados à instituição em primeira instância. Portanto, os fatores de coesão modificam-se em um contexto de interdependência funcional.

A perspectiva tocquevilliana é totalmente desfavorável à caridade pública, privilegiando as ações privadas, visto que considera que aquela primeira perpetua "o ócio entre a maioria dos pobres". Neste sentido, Tocqueville (2003, p. 101) descreve a posição do assistido a partir de uma noção negativa: "Ele olha para o futuro como um animal. Absorvido pelo presente e nos afazeres efêmeros e ignóbeis que ele fornece, sua natureza brutalizada não está consciente dos determinantes de seu destino".

A caridade pública, então, degrada ainda mais a condição do assistido que vive a vida para suprir suas necessidades mais básicas. Se o ócio e os vícios já são condenáveis entre aqueles que trabalham, os mesmos assumem uma conotação ainda mais negativa entre os que são viciosos à custa de trabalho alheio.

Tocqueville (2003, p. 109) resume sua posição crítica à caridade pública: 
[...] todos os abusos que tentei descrever estão contidos neste princípio [obrigação de alimentar os pobres], assim como uma grande árvore está contida em sua semente. Ela apenas precisa de tempo para se desenvolver e crescer. Querer criar uma lei que, de forma regular, permanente e uniforme, atenue a indigência sem, no entanto, aumentar a população de indigentes, sem aumentar sua preguiça e suas necessidades, seu ócio e seus vícios, é plantar uma semente e surpreender-se quando um caule, seguido de folhas, flores e frutos, os quais, por sua vez, um dia irão dar origem a uma floresta inteira.

Ademais, ao final do seu texto, Tocqueville (2003) expressa um dilema: a caridade pública é o "caminho natural" da civilização na atenuação da pobreza, mas contém o efeito colateral de ser produtora da "mentalidade do assistido", ou seja, a postura de dependência do recurso público. Por outro lado, a caridade privada, embora náo apresente o mesmo efeito negativo da primeira, é excessivamente limitada para atenuar, de forma eficaz, os sofrimentos decorrentes do crescimento da pobreza.

Desta forma, Tocqueville (2003) termina seu texto sem uma solução e sem uma posição definida. Ele reconhece, no entanto, a utilidade da caridade pública nos casos dos males inevitáveis, tal como a carência infantil, a decrepitude da velhice, a doença e a insanidade. Fora isso, os casos de calamidade pública também devem ser assistidos pelo Estado. Por fim, um último tipo de ação pública recairia na educação infantil, uma vez que esta garante "[...] os meios de suprir as necessidades físicas básicas através do trabalho" (TOCQUEVILLE, 2003, p. 110).

A posição do autor, portanto, tem como foco a crítica à assistência pública aos indivíduos aptos para o trabalho. Para os incapazes, para as calamidades e quando a ação é mais formativa que de assistência propriamente dita, o autor considera legítima a açáo do Estado. Seguindo os preceitos liberais, os indivíduos devem ser capazes de sustentarem-se a si mesmo, mediante suas capacidades e seus méritos.

As questôes sinalizadas por Tocqueville (2003) configuram elementos estruturais da ação assistencial moderna. A coexistência entre o direito à assistência - com a açáo estatal, e as ações institucionais e pessoais privadas neste campo - forja a mentalidade moderna da assistência social. Mesmo com a expansão das políticas de assistência social, as iniciativas privadas náo deixaram 
de existir. Mais do que isso, os Estados de Bem-Estar-Social expandiram-se com o fortalecimento da rede privada de assistência.

Nas açôes de cunho estritamente privado, há uma dupla caracterização: aquelas que são realizadas estritamente por agentes individuais apresentam elementos diferentes das açóes institucionais. No primeiro caso, há um envolvimento direto e pessoal entre assistente e assistido. E essa ação passa a conter um caráter "virtuoso" na medida em que ela se torna uma opção do agente. No mundo moderno, ninguém é pessoalmente obrigado a realizar assistência social a terceiros. A relação estabelecida, entáo, gera uma dependência precária (já que não irá se reproduzir indefinidamente e não se configura como direito) entre os agentes. A ação ocorre segundo a lógica do favor, tendo o assistente o poder de iniciar ou finalizar a ação quando quiser. As demonstraçóes de gratidão e reconhecimento por parte do assistido são fundamentais para a continuidade do atendimento. Como se verá a seguir, as açôes privadas não se estruturam táo somente na lógica do favor, mas também do paternalismo e da tutela.

Esta forma de ação sofre uma nuance ao ser institucionalizada. Ela se modifica mais ou menos conforme o grau e institucionalização da assistência. A institucionalização significa que as normas e regras institucionais passam a ter tanta ou mais importância (quando o processo burocratiza-se) que a ação dos indivíduos. Com a mediação das regras e normas, há um processo de despessoalização ${ }^{8}$, ou seja, a regra será cumprida independentemente de quem seja o assistente e de quem seja o assistido. Diminui, desse modo, consideravelmente a importância do carisma na ação assistencial, embora não diminua seu caráter virtuoso.

De todo modo, as lógicas do favor (do paternalismo e da tutela) permanecem vigentes nas açôes institucionais privadas, embora, de forma menos explícita. A grande diferença, neste caso, está em que o assistido deve adequar-se às normas institucionais, sem recorrer de forma tão direta ao escrutínio do agente. Nesse sentido, as regras funcionam como anteparos ao sentimentalismo do assistente: uma vez que a instituição não prevê determinado tipo de atendimento, resta ao assistente encaminhar o assistido para outra instituiçáo.

8 Para Marshall (1967, p. 148) a assistência social "[...] refere-se a um serviço que é pessoal, e de um caráter geral, ao invés de especializado"; portanto, ela contém elementos de pessoalização. 
O grande desafio das instituiçóes privadas de assistência é o de criar "portas de saída" para a população assistida, rompendo com a possível dependência instituída pela concessão dos benefícios sociais prestados aos assistidos.

Um fator presente nas instituiçóes públicas e privadas de assistência social é a profissionalização da atividade assistencial. A atuação profissional neste campo é um elemento muito controverso, uma vez que a assistência social não se configura como uma profissão, mas como um campo de atuação. Neste sentido, qual a expertise requerida para esta área? Quais as profissóes disputam este campo?

Embora haja controvérsias, a profissionalização é um segundo anteparo entre o sentimentalismo do agente e o assistido na prática assistencial. Por envolver um contrato e uma remuneração, a profissionalização pode acarretar agregação de agentes cujos interesses estejam mais voltados para a garantia do emprego (ou qualquer outro) do que com o objeto da assistência em si. Além disso, contrato e remuneração dão ao agente a legitimação da ruptura afetiva com o assistido, ou seja, o agente desempenha sua atividade como profissão e não como vocação (para utilizar um termo weberiano). Dessa forma, não é exigido do agente um envolvimento pessoal e afetivo com o assistido (ou com sua causa), mas a competência no cumprimento da tarefa que lhe for designada (execução dos benefícios sociais).

Cabe comentar que essas características derivadas da profissionalização da assistência não significam a completa ruptura afetiva na ação assistencial. Elas indicam um campo de possibilidades. Sua vigência depende de como o próprio profissional porta-se no campo. Há uma gradiente de possibilidades que vai desde a completa indiferença afetiva pelo outro - sendo a ação o resultado tấo somente das técnicas profissionais - até a utilização do espaço profissional como campo de militância social e de envolvimento pessoalizado com o assistido. Entre os extremos, há um conjunto de possibilidades que são definidos ad hoc.

Por fim, a assistência como um direito não é uma condição tão simples quanto Tocqueville (2003) pensava. Primeiro, porque a existência do direito não assegura, imediatamente, que seja atendido. E ainda que venha a ser, conforme determinada política de estado, nada garante a vigência indeterminada dessa mesma política. Acrescenta-se que a manutenção de políticas de longo 
prazo, no campo assistencial, sem a previsão de superação do estado de necessidade do assistido é uma pré-condição assinalada pelo autor para a formação de um tipo de mentalidade (de acomodação) entre os assistidos.

Ressalta-se que a formalização legal da assistência como um direito depende, não somente de existência de lei mas da sua vigência. De outro modo, é preciso que os agentes executores das políticas de assistência institucionalizem práticas que consolidem a assistência como um direito em seu fazer cotidiano. Essa vigência é um campo de possibilidades, visto que, uma vez instituída como direito, a assistência pode (ou não) ter esse tipo de vigência.

De um lado está a forma como as políticas de estado se estruturam; de outro, a concepção que os agentes (profissionais e voluntários) têm da assistência. Estabelecido esse ponto de partida, é preciso analisar a forma como assistentes e assistidos colocam-se na prática assistencial. Estes dois pontos serão objeto de análise nos próximos itens.

\section{Relações de poder social}

A forma como a assistência social é executada não depende somente dos elementos que a estruturam. Parte da explicação deriva da maneira como os agentes compreendem e transformam essa compreensão em prática social. Entretanto, há ainda um elemento "estrutural" da ação assistencial: ela se configura como uma relação de poder e de dominação.

Conforme analisado por Tocqueville (2003), a assistência decorre de uma relação de desigualdade social: o apelo à assistência é uma confissão de incapacidade. Neste sentido, apenas será assistido aquele que não tiver capacidade de resolver, por si mesmo, aquilo que reivindica como objeto da assistência.

Além disso, nem toda assistência é social. Há, também, a assistência educacional, de saúde, religiosa, entre outras, variando sempre o objeto de incapacidade do indivíduo. No caso da educação, um aluno que não apresenta bons resultados pode ter "reforço escolar", ou seja, uma assistência educacional complementar para suprir sua dificuldade. Se o aluno considera, entretanto, que algumas horas a mais de dedicação ao estudo serão suficientes para que ele, sozinho, supere sua limitação, ele não irá recorrer à assistência. O mesmo vale para a saúde. Se alguém tem um resfriado e considera que pode suportá-lo sem a ajuda de um médico, então, tomará suas próprias providências. Caso 
contrário, buscará a assistência médica em meu auxílio. Por fim, no campo religioso, se alguém se considera muito religioso, pode crer que suas oraçôes, ao fim do dia, são suficientes para manter sua religiosidade. Mas se a pessoa se considerar incapaz de orar sozinha ou se considerar que suas oraçóes não são suficientes para manter a religiosidade, entáo, recorrerá à assistência ${ }^{9}$ de uma pessoa que a oriente nesse sentido.

No caso da assistência social, o objeto da assistência é, especificamente, o social. Mas do que trata? Há duas concepçóes de "social". A primeira é que o social engloba as dimensões da educação, saúde, habitação etc., ou seja, o social não seria um campo em si, mas um conjunto de elementos sociais. Outra concepçáo trata o social como uma "questáo" decorrente das contradiçóes do capitalismo; portanto, teria um sentido próximo ao anterior, constituindo em um conjunto de elementos (sem estarem encerrados em um campo específico), estando eles agregados às contradições derivadas da relação capital versus trabalho ${ }^{10}$.

O social, neste artigo, será considerado em duas dimensôes: a primeira dimensão em relação à pobreza; a segunda, referente aos vínculos sociais. No que tange ao primeiro caso, parte-se da concepçáo relativa de pobreza tal como se encontra em Simmel e Jacobson (1965). Quanto ao segundo caso, a referência principal é o texto de Castel (1997).

Com relação à pobreza, Simmel e Jacobson (1965) adotam duas concepçóes: existe o pobre, em geral, e o pobre que recebe assistência (assistido) ${ }^{11}$. Qual a diferença entre os dois? Simmel e Jacobson partem de uma concepçáo relativa de pobreza, ou seja, um indivíduo é pobre se "os seus meios não são suficientes para atender suas necessidades" ${ }^{\prime 2}$. No entanto, os próprios autores reconhecem a limitação do conceito expresso, uma vez que, há necessidades que podem ser consideradas independentemente de qualquer decisão pessoal. São os casos das "necessidades básicas", como alimentação, vestimenta e abrigo. $\mathrm{O}$ conceito desses autores é sobre a pobreza e não sobre a fome ou outro conceito que diga respeito ao limite da incapacidade de autorreproduçáo dos

9 Sobre assistência religiosa, ver Simões, 2010

10 A crítica a ambas as posições pode ser encontrada em: Latour, 2012.

II A quem chamarei, daqui em diante de assistido.

12 "He is poor whose means are not sufficient to attain his ends" (SIMMEL; JACOBSON, 1965, p. 136). 
indivíduos. É nesse sentido que o autor afirma que a determinação do nível das necessidades a serem contempladas pelos indivíduos é relativa ao contexto histórico-cultural. Para Simmel e Jacobson (1965), o pobre é aquele que está nos estratos mais baixos dos grupos sociais, não atingindo os níveis mínimos que determinados pelo grupo. Então, o pobre é aquele que está e se vê aquém dos demais. Sua concepção avança no sentido do paradoxo tocquevilliano: em um ambiente de fartura e prosperidade aquele que tem pouco pode sentir-se inferiorizado; mudando de contexto, para um ambiente de carência, o pouco pode ser considerado o ótimo, ou ainda, não despertar um sentimento de inferioridade no indivíduo, uma vez, que os demais membros do grupo também detêm poucos recursos (TOCQUEVILLE, 2003).

O caráter relativo da pobreza deriva em uma concepção subjetiva: na medida em que "[...] um homem realmente pobre não sofra com a discrepância entre seus meios e as necessidades de sua classe, então, a pobreza, em seu sentido psicológico, não existiria para ele" (SIMMEL; JACOBSON, 1965, p. 136) ${ }^{13}$. Neste sentido, um indivíduo pode não sentir-se pobre ainda que tenha privação de recursos ${ }^{14}$, segundo o contexto em que vive. Desta forma, o pobre não se torna um assistido e, além disso, passa a ter uma invisibilidade ${ }^{15}$. Essa discussão tem relação, embora não esteja no texto de Simmel e Jacobson, com a ética protestante e os princípios do self-made-man. Segundo Barbosa (1989), Tocqueville mostra, em "A Democracia na América (1987)", como os Estados Unidos foram construídos a partir da comunidade para o estado e do estado para uniáo. Assim, associada à ética protestante, criou-se uma "cultura baseada no mérito" e na capacidade empreendedora dos indivíduos (BARBOSA, 1999). É no bojo dessa cultura que o indivíduo, a despeito da sua condição de privação social, pode buscar em suas habilidades, em seus meios e em sua rede social, formas de superação da situação por que passa independentemente de qualquer recurso estatal. Ele permanece pobre sem ver-se como assistido.

13 "A man Who is really poor does not suffer from the discrepancy between his means and the needs of his class, so that poverty in the psychological sense does not exist for him" (SIMMEL; JACOBSON, 1965, p. 136).

14 "It may be, therefore, that individual poverty - insufficiency of means for the ends of a person - does not exist for someone, while social poverty exist" (SIMMEL; JACOBSON, 1965, p. 136).

15 Os autores afirmam que, em um contexto de classe social, os preceitos de classe podem ser fortes o bastante para tornar a pobreza invisivel. 
Castel (1997) denomina esta pobreza como pobreza integrada: ela é constituída pelos trabalhadores pobres. Embora tenham emprego e sejam trabalhadores, são eles que estão nos estratos sociais mais baixos, ocupando as profissôes com menor status e retorno financeiro. Essa é a pobreza que é derivada diretamente do acesso diferenciado à educação e à estratificação das profissôes. Ela é, portanto, plenamente legitimada socialmente. Simmel e Jacobson (1965) afirmam que esses trabalhadores também passam desapercebidos no grupo social, porque não são vistos como pobres, mas de acordo com suas ocupaçóes e dentro da interdependência funcional da sociedade.

O importante a considerar é que, para Simmel e Jacobson (1965), os limites da pobreza e a identificaçáo de quem é o pobre são estabelecidos no contexto de cada classe social, a partir de critérios do próprio grupo. Neste sentido, a pobreza é um desnível social dentro de um mesmo grupo, ou seja, é constituída por uma camada social do grupo que, mesmo pertencente àquele grupo, não consegue os requisitos mínimos estabelecidos internamente. Embora com um approach diferenciado, Simmel e Jacobson (1965), chegam a uma conclusão semelhante a de Tocqueville (2003) no que se refere à existência de uma diferença social significativa que caracteriza o pobre dos demais membros do grupo social, ou na concepção de Bourdieu (2008), uma distinção.

O que torna o pobre um assistido é a própria aceitação da assistência ${ }^{16}$. Essa aceitação, no entanto, significa uma comprovação de que a pessoa pobre é formalmente um desclassificado [déclassé] - perdeu a sua condição na classe social à qual pertencia, aceitando uma condição inferior aos demais. Nesse sentido, Simmel e Jacobson (1965) invertem a relação: não é a pobreza que vem primeiro e depois a assistência, mas a assistência é a própria institucionalização da pobreza, transformando o pobre em assistido. Portanto, esses autores entendem a pobreza não como um estado quantitativo, mas somente como derivado de uma relação social.

A sociologia apresentada refere-se ao interacionismo simbólico ${ }^{17}$ : "o indivíduo é determinado pela maneira como a totalidade que o cerca age sobre

16 "Ninguém é socialmente pobre, até que ele seja assistido" (SIMMEL; JACOBSON, 1965, p. 138).

17 A escola do interacionismo simbólico tem como seus representantes autores como Berger e Luckman (20 II). 
ele" (SIMMEL; JACOBSON, 1965, p. 138) ${ }^{18}$. Aceitar a assistência é, portanto, colocar-se no lugar do pobre assistido (e não do pobre integrado ou do pobre invisível) e passar a estabelecer uma relação de desigualdade com os demais. Ou, ainda, nas palavras dos autores: "[...] somente quando a sociedade - a totalidade ou os indivíduos particulares - tem a reação de assisti-lo, só assim, ele desempenha seu papel social específico" [de pobre] (SIMMEL; JACOBSON, 1965, p. 138) ${ }^{19}$.

Essa condição de assistido tem fundamento tanto para os níveis mínimos estabelecidos no interior de cada classe, como também para as questóes relativas à vulnerabilidade social e ao risco social. O debate sobre esse tema é institucional, ou seja, no Brasil, foram as agências de governo que estabeleceram essa ampliação da concepção do assistido, por meio do SUAS (Sistema Único de Assistência). E quem desenvolveu o conceito de vulnerabilidade social é Castel $(1997)^{20}$.

Ao analisar a inclusão social tendo como referência o conceito de vulnerabilidade social, o âmbito da assistência se ampliou, significativamente, se comparado à concepção da pobreza (ou do assistido). Para promover essa ampliação, Castel (1997, p. 23) propóe um duplo processo de desligamento social: em relação ao trabalho e em relação à inserção relacional: assim, "[...] todo indivíduo pode ser situado com a ajuda deste duplo eixo". O primeiro eixo engloba uma hierarquia, constituída de "trabalho estável", "trabalho precário" e "não trabalho"; o segundo, considera uma "inserção social forte", "fragilidade relacional" e "isolamento social". Associando esses dois eixos, formam-se três zonas: a zona de integração, a zona de fragilidade e a zona de desfiliação.

A zona de integração é formada pelos "[...] grupos [que] gozam de uma grande segurança no emprego e integram fortes e coerentes redes de dependência". "São pobres, mas não suscitam problemas" (CASTEL, 1997, p. 23); a zona de vulnerabilidade "[...] compreende trabalhadores independentes sem

18 " $[\ldots]$ the individual is determined by the way in which the totality that surrounds him acts toward him" (SIMMEL; JACOBSON,, 1965, p. 138).

19 "Only when society - the totality or particular individuals - reacts toward him with assistance, only then does he play his specific social hole" (SIMMEL; JACOBSON, 1965, p. 138).

20 O debate sobre vulnerabilidade e risco social realizado por Castel (1997) não parte do suposto interacionista como será observado. A discussão desses conceitos tem como base um fundamento durkheimiano de anomia social (DURKHEIM, 1995). 
reservas econômicas [...]. Sua instabilidade é crônica e eles estão ameaçados a passar para a terceira zona" (CASTEL, 1997, p. 23); a zona de desfiliação é composta basicamente pelo "vagabundo": ele não trabalha apesar de poder trabalhar e está cortado de todo apoio relacional (CASTEL, 1997). Além dessas quatro zonas, Castel ainda acrescenta uma última denominada de "zona de assistência". O que difere a zona de desfiliação e a zona de assistência é que no primeiro caso há um duplo desligamento: em relação ao trabalho e em relação à inserção relacional. No entanto, "[...] o tratamento dispensado ao vagabundo difere totalmente daquele dispensado ao inválido que não pode trabalhar" (CASTEL, 1997, p. 24). Se o indigente inválido é conhecido pela comunidade, ele será assistido e terá quase sempre um suporte social. Desta forma, afirma o autor, a "zona da assistência" tem como base "[...] uma proteção aproximada, fundada no princípio da 'casa de caridade" (CASTEL, 1997, p. 24). E essa zona não se revela como um "problema social".

A reflexấo de Castel (1997) aponta para a necessidade de se atuar especificamente na zona de vulnerabilidade. Nela, os indivíduos ainda detêm algum tipo de vínculo social, mas este último se encontra fragilizado. Então para o autor, é preciso que os indivíduos não ultrapassem esse limite, tornando-se desfiliado ou assistido.

A discussão de risco social veio associada à de vulnerabilidade; todavia, ela é, necessariamente, maior do que aquela restrita ao campo da assistência. O principal autor desta linha argumentativa é Beck (2013). Esse autor não se reporta a situaçóes específicas referente a famílias e indivíduos que estejam "em situaçáo" de risco social. Ele enfatiza que estamos inseridos (desde o início do século XXI) em um contexto societário de risco, visto que vivenciamos situaçóes-limite, como a crise ambiental e as catástrofes nucleares, que colocam em risco toda a humanidade, independentemente de classe social.

De todo modo, a noção de risco foi incorporada ao debate sobre assistência para designar os indivíduos e as famílias que se encontram na iminência de "algo" pior: desemprego, quebra de laços sociais, violência doméstica etc. Há, portanto, uma imprecisão na utilização desse conceito que não foi pensado para esse fim. Além disso, o "risco" social, também utilizado na área da saúde para designar o risco (de morte) ante uma operação, por exemplo, não chega a ser medido ou mensurado, permanecendo mais como discursividade do que como um "diagnóstico" social. 
Essa análise é o fundamento para a ampliação da atuação das políticas e açóes assistenciais para além das questóes relativas à pobreza, incorporando, também, um conjunto mais amplo de grupos sociais, em situação de vulnerabilidade, detendo, não apenas recursos escassos em relação ao grupo social ao qual pertencem, mas também vínculos sociais (com a família, a comunidade, o trabalho, entre outros) em vias de rompimento. Tudo isso, resulta em três questóes: 1) como a sociedade prepara-se para atuar na assistência social?; 2) Qual a posição daqueles que assistem?; 3) Qual a posição daqueles que são assistidos?

\section{I A posição da sociedade}

Como ponto de partida deste item, é preciso esclarecer que se entende por "posição da sociedade" os grupos sociais (instituições religiosas, de bairro, entre outras) ou o Estado que vão atuar no sentido de minimizar os efeitos da pobreza ou da vulnerabilidade social.

$\mathrm{Na}$ sociedade moderna, a assistência passa a ser um direito social e são criadas políticas para atender a este direito. A fonte de recursos para essas políticas provêm daqueles que não necessitam de assistência, através da lei e dos impostos. Neste sentido, o assistido é um objeto da açáo dos outros e ele se coloca nesta posição na medida em que demanda a assistência. A "sociedade" decide, então, como irá atender à demanda daqueles que reivindicam assistência.

É partindo desse pressuposto que a relação entre assistente-assistido se torna uma relação de poder ${ }^{21}$. A "sociedade" passa a ter a prerrogativa de especificar como e o que fará diante do pobre que demanda assistência. Um exemplo simples pode ser observado quando, em razão da incapacidade de ação, uma pessoa pede auxílio a outra (uma assistência). Vamos supor que estejamos falando de um exercício matemático. Então, supondo que a pessoa que prestará um auxílio sabe algo que o que assistido não sabe e que, seguindo as suas orientaçôes, este também será capaz de realizar o cálculo. Nessa hora, a relação (que era entre iguais) muda sua configuração, tornando-se uma relação entre desiguais. Aquele que sabe poderá impor condiçóes (como a realização

21 Parte-se aqui da concepção de poder, conforme Foucault (20/2). 
de exercícios prévios) para ensinar o que o assistido demanda saber. Desta forma, a prerrogativa da açáo é do assistente, sendo o assistido o objeto dela.

Simmel e Jacobson (1965) chamam atenção para o caráter peculiar das ações assistenciais: elas diferem das demais (educação, saúde, entre outras) que são pensadas para todos os cidadãos, em igualdade de condiçôes. A atuação social é a única em que não atua a partir de um princípio universal, mas tendo como parâmetro uma desigualdade social entre os membros do grupo.

Desta forma, no âmbito da sociedade, Simmel e Jacobson (1965) defendem que os grupos sociais atuam instrumentalmente, ou seja, a assistência é um meio de atender à demanda de um grupo (os assistidos) de modo a não comprometer a ação dos demais membros da sociedade. Afirmam os autores: "[...] a assistência é baseada na estrutura da sociedade, seja ela qual for; [...] o objetivo da assistência é precisamente mitigar certas manifestaçóes extremas da diferenciação social, então a estrutura social pode continuar baseada nesta diferenciação" (p. 122). Para os autores, o que está em foco é o "interesse da sociedade" e não o interesse dos pobres. Caso o foco fosse, de fato, estes últimos, então, a açóes assistenciais deveriam realizar transferências de renda e propriedade de forma a buscar uma igualdade social. Assim, a assistência, antes de ser um direito do pobre, ela o é de "[...] cada cidadáo que paga as taxas para que a pobreza seja de um tamanho tal e aplicada de tal maneira que os objetivos públicos da assistência para o pobre sejam atendidos verdadeiramente" (SIMMEL; JACOBSON, 1965, p. 122).

Por fim, Simmel e Jacobson (1965) asseveram que há uma razão utilitária para que a "coletividade" atue na assistência: a mobilidade descendente de um ou mais indivíduos poderia resultar na perda de status para a coletividade. Todos esses elementos demonstram que o assistido deixa de ser um fim da ação assistencial, para tornar-se um meio. O fim é o melhor funcionamento da sociedade e a ação assistencial ajuda a promovê-lo.

Então, quem age assistencialmente o faz tendo por base o egoísmo? Sim e não. Inicialmente, há que considerar a posição de poder do assistente: é ele quem determina como será a açáo desenvolvida, podendo estabelecer condicionalidades para acesso dos assistidos aos bens e serviços ofertados. Neste sentido, o ponto de partida da assistência é o próprio assistente que se dispóe a agir, mas sob suas condições. 


\subsection{Assistente / Assistido ${ }^{22}$}

O ponto de análise, agora, volta-se especificamente para a relaçáo entre assistente / assistido. De partida, é preciso afirmar que esses atores estáo em relação e que, portanto, náo faz sentido analisar a forma como um age, sem considerar o outro.

Assim como para a sociedade, Simmel e Jacobson (1965) também estabelecem, para o agente da assistência, uma posiçáo utilitária. Conforme os autores, o foco do agente é o seu dever moral; para isso, eles recorrem à passagem bíblica quando Jesus dialoga com o homem rico, afirmando: "dá suas riquezas para os pobres". Com essa expressão, segundo os autores, Jesus não se voltava para o assistido que receberia as riquezas, mas seu alvo era a salvação do rico. Neste sentido, afirmam: "a esmola cristã manteve o mesmo caráter", pois "aumentavam as chances de salvação dos doadores" (SIMMEL; JACOBSON, 1965, p. 121).

Por outro lado, o assistido, ao observar sua posição de desvantagem social, percebe todos aqueles que têm mais que ele como agentes que retiram dele aquilo que deveria ser seu por direito. Buscam, assim, uma compensação, ou entre indivíduos mais abonados, ou nas instituiçôes. A própria concepção de direito faz com que o assistido deixe de envergonhar-se por receber a assistência. Para Simmel e Jacobson (1965), há um dualismo que governa a ação assistencial, com base na díade: direitos e deveres.

Essa tensão volta-se para uma questão sociológica de fundo: o debate entre autores do individualismo metodológico, como Elster (1994) e autores da antropologia, derivados do debate de Marcel Mauss sobre a dádiva, como Godbout (1999). Para o primeiro, só existe o "comportamento não-egoístico (sic) puro" quando ele é representado por "contribuiçōes anônimas a obras de caridade impessoais" (ELSTER, 1999, p. 74), ou seja, quando não há qualquer tipo de autorretribuição (ou interesse) na ação desempenhada. Nesse sentido, este tipo de ação é bem mais difícil do que parece, principalmente, devido ao anonimato do agente. Sem essa condição satisfeita, a ação, aparentemente altruísta, guardaria, em alguma medida, um traço de ação racional

22 Parte dos argumentos aqui apresentados foram desenvolvidos originalmente em Simões (2009). 
ou instrumental - o agir para beneficiar-se da ação, como no exemplo bíblico do moço rico.

Por outro lado, Godbout (1999) critica a concepção apresentada por Elster (1999), embora não cite este diretamente. Para Godbout (1999, p. 15), sempre é possível argumentar que na ação altruísta há uma forma de prazer para o agente que a executa; no entanto, "[...] esse egoísmo, cuja satisfação passa pelo altruísmo, é bastante diferente do egoísmo primitivo e tosco do qual a modernidade postula a universalidade". $\mathrm{O}$ argumento do autor, entretanto, não se resume a este ponto, visto que ele afirma que - como um contraponto à ação racional e calculista moderna -, a dádiva só poderia existir, dentro da concepção típico-ideal da ação racional, se ela fosse o seu oposto, ou seja, gratuita (GODBOUT, 1999). Como a total gratuidade é impossível, então, a dádiva não existiria? A partir dessa concepção, o autor comenta que, de fato, uma ação, nestes termos não existe. Entretanto, Godbout conceitua a dádiva como uma forma de estabelecer uma relação em que se age "sem esperança de retorno", em "sentido único", pois independentemente do egoísmo ou do altruísmo,

[...] da antítese fixada entre um momento considerado ideal, porém inacessivel do desinteresse radical, é preciso pensar na dádiva não como uma série de atos unilaterais e descontínuos, mas como relação" (GODBOUT, 1999, p. 16).

O ponto central, então, da sua argumentação é que a dádiva é uma forma de relação que estabelece entre quem pratica e quem recebe uma forma de vínculo. A criação do vínculo, já discutida a partir de Tocqueville (2003), está no contraponto da ação contratual, em que a associação entre os indivíduos é puramente formal, sem envolvimento emocional, terminando tâo logo termine o contrato. A dádiva, ao contrário, é uma expressão de interesse entre as partes, tendo um caráter mais simbólico que monetário. Então, ao se aproximar do outro, a dádiva, na forma do presente ou da doação, sem expectativa de retorno imediato, seria uma forma de criação de vínculo entre as partes.

A ação assistencial seria uma forma de dádiva? Ou seria uma ação instrumental? Destaca-se que os autores que enfatizam a forma de se realizar a assistência não entram nessa questão diretamente, deixando-a em aberto. A ênfase recai nos tipos de uso do poder que o assistente detém diante do assistido e na forma como este último pode agir diante do ato de dominação, tal como a tutela e o paternalismo. 
Castel (1998) refere-se a vínculo moral entre assistido e assistente como uma açáo tutelar. Para o autor, esse tipo de açáo teve seu ponto de partida no século XIX, especificamente na França, quando os cuidados das "classes inferiores" foram realizados por uma política "sem Estado", na qual as elites sociais eram as responsáveis pela beneficência e pela caridade. Essa é uma forma como a assistência traduz-se em uma ação de poder.

A beneficência é, para Castel (1998), uma forma de tutela baseada em um dever moral com a ordem pública, uma ação ética, e não necessariamente política. Assim como o pobre, na concepção de Tocqueville (2003), deve incorporar sua condição de inferioridade; na ação tutelar, a beneficência está voltada para os grupos em situaçáo de menoridade. Os grupos assistidos são aqueles que precisam de ajuda, pois estão na mesma condição da criança que não se basta a si mesma, que é dependente de terceiros para o provimento de suas necessidades ${ }^{23}$.

Por outro lado, na ação profissional e, mesmo pública, em que existe um contrato social estabelecido entre assistido e assistente, há também uma ação tutelar. No entanto, essa nova tutela se dá pelo desnivelamento entre os sujeitos da ação que impede uma troca recíproca entre eles: entre o rico e o indigente, o competente e o ignaro, o médico e o louco, o civilizado e o indígena. Essas tutelas, que podem ser passageiras ou permanentes, revelam e traduzem a legitimidade do saber, em um contexto de especialização do trabalho.

Sennett (2001) afirma que o elo moral existente entre o assistente e o assistido pode se traduzir em uma açáo paternalista. Para o autor, o paternalismo é uma forma de dominação masculina em que o "patrão" confunde-se com a figura do pai. Na sociedade paternalista, os "pais" não podem assegurar a seus "filhos" um lugar conhecido no mundo, mas podem agir como seus protetores. Assim, os assistentes sociais, ou melhor, os profissionais responsáveis pela assistência social, ao agirem na busca de garantia dos direitos de seus usuários, podem também agir como seus protetores, assumindo a figura de um "pai", ou de uma "mãe".

23 "Uma política moral é necessária, ou, o que dá no mesmo, uma política social é necessariamente de natureza moral, na medida em que está voltada a grupos em situação de menoridade. Essa analogia entre o povo e a criança é o leitmotiu de todos aqueles que se debruçam sobre o destino das classes inferiores [...]" (CASTEL. 1998, p. 305). 
Há um pressuposto na ação paternalista, enfatizado por Sennett (2001), que afirma que a eficácia do "pai" substituto ocorre apenas quando o pai natural fracassa e se a liberdade da pessoa em tratamento, ou objeto da ajuda, for cerceada. Isso significa que o assistido deve obediência ao seu assistente, pois é este último que sabe o que o assistido deve fazer para poder ser ajudado. $\mathrm{O}$ assistente pode e deve influenciar, aconselhar, encaminhar, (des)motivar etc. o seu assistido, mas a recíproca não é verdadeira. Há uma evidente relação de oposição entre autonomia e liberdade versus assistência. O que está "em jogo" é a ação moral que o assistente exerce sobre o assistido, o que retira a liberdade de escolha e de ação deste último, em decorrência da aceitação da ajuda recebida.

Sennett (2001) acrescenta que, embora possa haver uma relação paternalista entre assistente e assistido, a assistência social estabelece uma necessária relação de dependência social. Na visão liberal, a necessidade de assistência é o reconhecimento de um fracasso pessoal. $\mathrm{O}$ melhor dos mundos, nessa perspectiva, seria aquele no qual ninguém precisasse depender dos outros e, muito menos do Estado; portanto, que as pessoas se bastassem a si mesmas e que fossem autossuficientes. Nessa linha de pensamento, a dependência ao governo gera uma infantilização dos adultos, fazendo com que eles se comportem como crianças. Novamente, há um desnivelamento entre o assistente e o assistido, provocando uma açáo desnivelada entre ambos e fazendo com que os usuários da assistência sejam vistos, pelos seus "benfeitores", como necessitados de ajuda, infantilizados, inferiores, carentes, dependentes etc.

Assim como os assistentes sociais podem assumir uma posição paternalista, tuteladora e superior aos seus assistidos, há, também, formas específicas destes últimos lidarem com a assistência. Quem discute essa outra perspectiva é Paugan(2003), em seu livro "Desqualificação Social". Neste livro, o autor enfatiza três formas como os assistidos lidam com a assistência social e como essas formas definem grupos específicos, ou tipos ideais, de usuários: os fragilizados, os assistidos e os marginalizados. Sem entrar na discussão acerca das características que demarcam cada um dos tipos, é preciso esclarecer que, para o autor, a condição de assistido social configura uma posição de degradação social e de reconhecimento social e institucional da pobreza e do pobre.

Paugan (2003) recorre a uma abordagem baseada em G. Simmel, na qual este último autor faz a associação entre pobreza e assistência; assim, Paugan 
rejeita as formas "tradicionais e empíricas" de definição da pobreza em favor de uma definição "institucional": os pobres são aqueles que institucionalmente são reconhecidos como tal, através da concessão da assistência social, conforme visto anteriormente.

O que Paugan (2003) enfatiza em seu trabalho, portanto, é que o reconhecimento social e institucional do pobre é uma degradação de status, uma vez que significa o reconhecimento social da incapacidade do indivíduo, tanto em relação à classe (renda ou poder econômico), ao status (prestígio e capital social) e ao poder ${ }^{24}$. Assim, não serão todos que irão aceitar essa condição da mesma forma, principalmente porque a aceitação da posição de pobre implica o aprendizado dos papéis sociais a ele atribuídos e do estabelecimento de uma relaçáo específica com o assistente social.

Segundo Paugan (2003), são os assistentes sociais os profissionais responsáveis pela designaçáo institucional do status de pobre. Aos assistentes sociais, cabe realizar um diagnóstico e construir uma biografia da situação que será oficialmente reconhecida, além de estabelecer metas de "reabilitação social", abrindo, aos usuários, direitos, acesso à renda e à obtenção de múltiplas vantagens. $\mathrm{O}$ usuário, por outro lado, pode ou não aceitar as imposiçôes institucionais designadas pelo assistente social de controle e regulação de sua vida privada.

Há, na designação do pobre e na aceitação desta nomeação, interesses em jogo que podem estar em conflito ou se somarem. Paugan (2003, p. 60) parte da seguinte hipótese:

[...] as classes auxiliadas ou assistidas negociam a inferioridade do seu status tentando, por exemplo, reinterpretar os traços negativos que o definem ou elaborar racionalizações para aceitar, ainda que temporariamente, as conseqüentes (sic) imposições.

Toda a argumentação de Paugan (2003) recai sobre as formas de negociaçáo do status do pobre, tendo como parâmetro o ponto de vista deste último. Vale ressaltar, outrossim, a forma como o autor concebe a posição do assistente social nesta negociação: partindo do trabalho de Verdès-Leroux (1982), afirma que os grupos populares desfavorecidos são

24 Referência ao texto de Weber (197I) 
[...] vítimas de seu [dos assistentes sociais] etnocentrismo de classe. Provenientes na maioria das vezes das camadas médias, analisam os traços característicos do modo de vida das classes populares como patológicos, o que tem por efeito, entre outros, enquadrar na assistência a fraca inferior e não qualificada dos operários, e assim estabelecer sua segregação. Para impingir seu sistema de valores e se impor à população que constitui o 'alvo' da ação social, exercem uma violência simbólica. (PAUGAN, 2003, p. 58).

Os valores dos assistentes sociais passam a ser considerados relevantes para o entendimento da ação assistencial por eles realizada. O ponto agora analisado, entretanto, está na negociação do status do pobre. Uma vez mais, coloca-se a questão: que valores estão na base da ação dos assistentes sociais? Todos os assistentes sociais provêm das camadas médias da população, como afirma Paugan (2003), tendo como parâmetro a realidade francesa? Somente os valores de classe interferem na prática profissional? E mais especificamente, se os "assistidos" negociam com os "assistentes sociais" o status do pobre, em que bases ocorrem essas negociaçóes?

Como se pode observar, a argumentaçáo de Paugan (2003), ao mesmo tempo em que reconhece a relevância dos valores dos assistentes sociais em suas práticas, não deixa de enfatizar a ação racional e instrumental de suas atividades. Os valores estão subjacentes às racionalidades estabelecidas no próprio fazer profissional e ficam, assim, encobertos por uma aparente objetividade.

O ponto defendido por Himmelfarb (1991) reafirma a posição que pode ser depreendida do pensamento de Paugan (2003). Para a autora, a assistência nascida na Inglaterra da era vitoriana deve ser vista como uma ação de compaixão ${ }^{25}$. Entretanto, o conceito de compaixão defendido por Himmelfarb (1991) se reporta a uma ação instrumental e não afetiva ou baseada em valores. Para a autora, a visão afetiva da compaixáo - relacionada aos sentimentos despertados pelas extremas condiçôes de dificuldade - faz parte das açôes caritativas e benevolentes, mas não da assistência social propriamente dita. É a compaixão sentimental que torna o pobre um dependente das ações de caridade.

Os reformadores sociais do final do século XIX na Inglaterra náo eram nem sentimentais nem utópicos em suas preocupaçóes públicas e privadas.

25 Uma discussão sobre compaixão encontra-se em Caponi (2000). 
Eles queriam dar um senso de proporção à compaixão, fazendo com que esta fosse compatível com os fins das políticas sociais. Isto significava dar um conteúdo mais racional que sentimental à compaixão, mais científico que emotivo. Himmelfarb (1991) chega a classificar esse novo tipo de compaixáo, como uma compaixão "propriamente entendida", fazendo menção ao conceito tocquevilliano de "interesse bem compreendido".

Tocqueville (1987) considera que o interesse não necessariamente se caracteriza como uma ação egoísta. A ação baseada no interesse "bem compreendido" é aquela em que a pessoa faz o bem ao próximo sem que isso seja motivo de um autossacrifício ou um autoflagelo ${ }^{26}$; assim, ao mesmo tempo em que ela ajuda ao outro, ela beneficia a si mesma. Trata-se de uma ação racional de alguém em que há um senso de proporçấo entre meios e fins, do que é bom para os outros e do que é bom para si mesmo ${ }^{27}$. É a partir desse entendimento que Himmelfarb (1991) trata a compaixão, agora traduzida na forma moderna de assistência social.

Logo, não se faz mais "o bem pelo bem", como resultado de um impulso emotivo, mas se atua buscando as formas racionais de fazê-lo, mesmo que estas possam terminar ferindo os sentimentos daqueles que a fazem. O que importa, ao fim e ao cabo, são os resultados obtidos e a melhor adequação entre os interesses privados e os interesses públicos, e náo o extravasamento do sentimento. Isso não significa que deixava de lado o sentimento na ação, mas que ela era, ao mesmo tempo, apaixonada e desapaixonada ${ }^{28}$.

Himmelfarb (1991), com essas observaçóes, recoloca a questão entre a ação assistencial ser uma ação baseada em valores ou uma ação racional. Desde os pioneiros do Serviço Social profissional, época de foco do trabalho de Himmelfarb, a ação filantrópica/beneficente religiosa e voluntária difere da assistência social, pois esta última torna-se um campo de trabalho profissional.

Por fim, há ainda um último tópico a ser tratado. O que faz com que o assistido aceite negociar o status de pobre com o profissional que o atende?

26 "Os moralistas americanos não pretendem que seja necessário sacrificar-se aos semelhantes porque é grandioso fazê-lo" (TOCQUEVILLE, 1987, p. 40I).

27 "[...] acredita-se afinal perceber que o homem, servindo aos seus semelhantes, serve a si mesmo, e seu interesse particular é fazer o bem" (TOCQUEVILLE, 1987, p. 40I).

28 "Compassion, properly understood, was at same time passionate and dispassionate" (HIMMELFARB, 199 I, p. 6). 
Como foi visto, ao aceitar a assistência, o assistido coloca-se em uma condição de inferioridade social e passa a ser submetido ao arbítrio, às condiçóes e imposições colocadas por aquele que realiza a assistência. Portanto, há uma perda de liberdade ao se assumir nesta condição.

Além disso, há um limite para assistência e esse limite é social. $\mathrm{O}$ que isso significa? Implica que o assistido náo pode receber mais do que outro indivíduo, em situação semelhante, conseguiria através do mercado. Por outro lado, não pode ser tão pouco que não eleve sua condição para que ele atinja o mínimo de referência ao grupo do qual faz parte. Um exemplo pode ser recuperado da assistência estudantil promovida pelas instituiçóes de ensino. $\mathrm{O}$ que se busca é dar condiçóes mínimas de estudo ao aluno, garantindo sua permanência na instituição. Não se busca, com isso, fazer com que o discente consiga fazer uma poupança com o dinheiro e os serviços recebidos, mas que não falte condiçóes para aquilo que é exigido para as atividades regulares de ensino.

Afirmam Simmel e Jacobson (1965, p. 130), “[...] quando os gastos são feitos em nome da coletividade, nada mais pode ser gasto do que o mais econômico dos seus membros gastaria". Os autores afirmam, ainda, que o estabelecimento do mínimo social é objetivo, ao contrário daquilo que excede a ele. Nesse caso, parte-se de "[...] um critério menos claro e depende de julgamentos subjetivos de quantidade e qualidade" (SIMMEL; JACOBSON, p. 131).

Toda a preocupaçáo aqui recai na possibilidade, também apontada por Marshall (1967), de não criar um desestímulo naqueles que têm menos na sociedade e não recorrem à assistência social, ou sejam, buscam suprir suas necessidades através do mercado. Simmel e Jacobson (1965, p. 132) afirmam que a assistência social pública têm como referência o mínimo social, ao contrário da assistência privada; assim, "[...] a desvantagem da assistência privada não está apenas no 'táo pouco' mas no 'demais', que leva à preguiça, utiliza os meios disponíveis de uma forma economicamente improdutiva e arbitrariamente privilegia uns em detrimentos de outros". A racionalizaçáo e a homogeneização dos recursos, através dos mínimos sociais, deveria ser, segundo os autores, uma prerrogativa dos trabalhos assistenciais.

Simmel e Jacobson (1965, p. 132), ainda, apresentam um exemplo, derivado da experiência inglesa, sobre o significado que a assistência social deveria ter para o assistido: 
A assistência social inglesa, ao entrevistar somente quando há uma determinação objetiva de absoluta carência de recursos, renuncia ao meio de investigação para analisar se uma pessoa merece ser assistida. Assim ocorre, uma vez que a vivência em um reformatório é uma experiência tão desagradável que ninguém, exceto em casos de extrema necessidade escolheria essa situação e, assim, consequentemente, a carência de recursos é objetivamente determinada.

Portanto, conforme expóem Simmel e Jacobson (1965), a busca pela assistência deve se dar somente quando não há uma alternativa possível, recebendo-se, tão somente, o mínimo social.

\section{Considerações finais}

Este artigo apresentou as principais questôes que envolvem a ação assistencial, constituindo uma base para a compreensão das atividades desempenhadas pelos grupos espíritas aqui analisados. $\mathrm{O}$ objetivo, então, é realizar uma síntese desses dilemas, a fim de à análise das concepçóes espíritas sobre assistência social.

Como foi visto, a assistência é uma atividade historicamente determinada, e que é empregada quando o "social" passa a ser uma questão para a sociedade e para o Estado. Ela tem um foco central: a pobreza e a vulnerabilidade social. Por isso, açôes públicas e privadas são realizadas no sentido de dar uma resposta da sociedade para os direitos daqueles que fazem parte da sociedade, mas estão nas faixas mais baixas dos seus grupos sociais ou encontram-se em uma situação de perda de laços sociais.

A assistência é uma designaçáo de um status inferior para parte do grupo social. Incorporar esse status é subordinar-se às práticas como o favor, a tutela e o paternalismo, além de permitir a regulação de esferas de sua vida privada. Assim, a assistência social implica uma relação de poder e cada um dos agentes busca atingir os objetivos da sua açáo. Entre os assistentes, o que predomina é a busca do cumprimento do dever e, nesse sentido, o assistido é apenas um meio para a realização do mesmo. Por outro lado, os assistidos submetem-se à ação assistencial, em parte, porque não encontram alternativas para suprir suas necessidades.

Nesse sentido, os assistidos negociam tanto o status de assistido, quanto o quantum receberão das práticas assistenciais que visam a garantir apenas o 
mínimo. Nas açôes públicas, o contrato reforça o individualismo de assistentes e assistidos; nas açôes privadas, cria-se um vínculo interpessoal difícil de romper, uma vez estabelecido.

Com Tocqueville (2003), as perguntam que ficam são: qual é a alternativa adequada para aqueles que são assistidos e para aqueles que se comprometem com a assistência? Deve-se perpetuar as relaçóes de poder, subordinando os mais "fracos" socialmente, à tutela dos mais "fortes" e ao seu arbítrio? A assistência é, de fato, nada mais que a gestão da pobreza, buscando preservar as formas de desigualdades no acesso a bens e a riquezas sociais? Afinal, será possível escapar das armadilhas e dos dilemas próprios da ação assistencial? Tais questionamentos demonstram que a ação assistencial envolve problemas difíceis de serem superados; afinal, sua aplicação tende a fomentar uma postura de dependência, produtora da "mentalidade do assistido".

\section{Referências}

BARBOSA, L. Igualdade e Meritocracia. Rio de Janeiro: FGV, 1999.

BECK, U. Sociedade do Risco. São Paulo: Editora 34, 2013.

BerGer, P.; LUCKMANN, T. A Construçáo da Realidade Social. 33. ed. Petrópolis: Vozes, 2011.

BOURDIEU, P. Distinção. São Paulo: Edusp; Porto Alegre: Zouk, 2008.

CAPONI, S. Da Compaixão à Solidariedade. Rio de Janeiro, FIOCRUZ, 2000.

CASTEL, R. A Dinâmica dos Processos de Marginalizaçáo: da vulnerabilidade à desfiliaçáo. CADERNO CRH, Salvador, n. 26-27, p. 19-40, jan./dez. 1997.

As Metamorfoses da Questáo Social. Petrópolis: Vozes, 1998.

DUMONT, L. O Individualismo. Rio de Janeiro: Rocco, 2000.

DURKHEIM, E. Da Divisão do Trabalho Social. São Paulo: Martins Fontes, 1995.

ELSTER, J. Peças e Engrenagens das Ciências Sociais. Rio de Janeiro: Relume-Dumará, 1994.

FOUCAULT, M. Microfísica do Poder. 25. ed. São Paulo: Graal, 2012.

GODBOUT, J. O Espírito da Dádiva. Rio de Janeiro: FGV, 1999.

HIMMELFARB, G. Poverty and Compassion. New York: Alfred and Knopf, 1991. 
LATOUR, B. Reagregando o Social. Bahia: Edufba, 2012.

MARSHALL, T. H. Cidadania, Classe Social e Status. Rio de Janeiro: Zahar, 1967.

MARX, K. Miséria da Filosofia. São Paulo: Livraria Editora Ciências Humanas, 1982.

PAUGAN, S. Desqualificaçáo Social. São Paulo: Cortez, 2003.

ROCHA, S. Pobreza no Brasil. Rio de Janeiro: FGV, 2003.

SENNETT, R. Autoridade. Rio de Janeiro: Record, 2001.

SIMMEL, G.; JACOBSON, C. The Poor. Social Problems, v. 13, n. 2, p. 118-140, autumn, 1965.

SIMÓES, P. Filhos de Deus. Rio de Janeiro: ISER; Brasília: SDH, 2010.

Gênero, Origem Social e Religiáo. Rio de Janeiro: E-Papers; FAPERJ, 2009.

TOCQUEVILlE, A. A Democracia na América. São Paulo: USP, 1987.

Ensaio sobre a Pobreza. Rio de Janeiro: UniverCidade, 2003.

VERDĖS-LEROUX, J. Trabalhador Social: práticas, hábitos, ethos e formas de intervençáo. São Paulo: Cortez, 1982.

WEBER, M. Ensaios de Sociologia. 2. ed. Rio de Janeiro: Zahar, 1971.

Recebido: 27.05.2015

Aceito: 01.08.2015

\section{Understanding the Assistential Action}

\section{Abstract}

The paper "Understanding the Assistential Action" focuses the social assistance in a sociological point of view and, particularly, on the action perspective. Thus, recovering the classical authors form the sociological thought - like Simmel e Jacobson, and Tocqueville-, seeks to nuance which elements make understandable the action, as: the context, the agents and the forms of actions, in addition the own object of assistance, the social. Following this thread, the paper is subdivided in three main parts: the approach to the social as a new question, established by the capitalism; the public and private actions and the assistance as a field of power relationships. By the end, the text shows that the assistential action closes difficult dilemmas to be overcome.

Keywords: Assistancial Action, Social Action, Social Assistance, Sociology 